\title{
Acquisition of Skills, Education Subsidies, and Agglomeration of Firms
}

\author{
Eric Toulemonde* \\ University of Lausanne
}

September 9, 2003

\begin{abstract}
We develop an analytically solvable model of new economic geography in which workers can choose to become skilled. Acquisition of skills is costly but allows to earn larger wages and can be subsidized by a regional government. For large transport costs, firms spread more or less evenly between both regions, their precise location being determined by the level of education subsidies. For low transport costs, firms agglomerate in one region. We also identify equilibria with partial agglomeration of firms. Finally, we show that the incentives to subsidy education largely depend on the level of transport costs.
\end{abstract}

JEL classification: F12, F15, J51, R12

Keywords: economic geography, education, subsidies.

${ }^{*}$ DEEP, HEC, Université de Lausanne. BFSH1, 1015 Lausanne (Switzerland). Email: eric.toulemonde@hec.unil.ch. 


\section{Introduction}

Economic geography models predict that mobile activities are agglomerated (resp. dispersed ) when transport costs are sufficiently low (resp. high) (Krugman, 1991; Fujita, Krugman and Venables, 1999; Neary, 2001; Ottaviano and Thisse, 2003). On the one hand, to save on costs involved in selling at a distance, manufacturing firms are willing to locate their production in regions where the demand for their product is large. Since the size of the demand in a region depends on the numbers of workers residing in that region, firms locate at proximity of workers. On the other hand, workers prefer to live in regions that have good access to the products that they consume. They want to reside at the proximity of manufacturing firms. As a result, manufacturing firms and workers may have an incentive to agglomerate in a single region (the core). The other region (the periphery) hosts firms and workers from the traditional sector.

Krugman and Venables (1995), Venables (1996) make the same point using an alternative framework in which workers do not migrate. Instead, an input-output structure explains agglomeration of manufacturing firms. Upstream firms prefer to locate their production at the proximity of their customers (the downstream firms) whereas downstream firms are attracted towards regions where they have a good access to their inputs. Again, a core-periphery structure may emerge: downstream and upstream firms agglomerate in the core region. ${ }^{1}$

More recently, these models have been adapted to study policy implications (see Baldwin et al., 2003 for a review). Issues on taxation (Ludema and Wooton, 2000; Kind, Midelfart Knarvik and Schjelderup, 2000), on public goods (Andersson and Forslid, 2003; Trionfetti, 2001), on trade agreements (Baldwin and Robert-Nicoud, 2000) are now under study. Questions such as how do these policies affect firms' location and how does firms' location affect these policies are analyzed. In this paper, we address the issue of educational policies. Is it fruitful for a local government to subsidy higher education in order to increase the supply of skilled labor in the region and attract new firms? To what extent is there a "subsidy competition" between

\footnotetext{
${ }^{1}$ The same type of results is also emphasized in Puga (1999).
} 
regional governments to raise the number of skilled workers and attract new firms? Do transport costs matter for these policies? These are the questions that are treated in this paper.

As Baldwin et al. (2003) explain, early models of economic geography are useful to illustrate the emergence of a core-periphery structure but are tedious to work with, forcing numerical simulations for most results, which makes them not suitable for the analysis of policy making. Therefore, Baldwin et al. (2003) develop alternative models that present most characteristics of the core-periphery model but are also analytically tractable ${ }^{2}$. Of these models the footloose capital model (initially developed by Martin and Rogers, 1995) displays agglomeration forces and allows to get a closed-form solution for the location of firms. However it does not display the circular causality that is at the center of the core-periphery models.

To study the issue of education we build a model that is inspired by the footloose capital model in which circular causality is re-introduced. The main difference with existing models is that agents have the choice of acquiring skills and working in a modern industry where goods are differentiated, or remaining unskilled and working in a constant returns to scale sector. Acquisition of skills is costly but can be subsidized by a regional government; moreover it allows individuals to earn wages that are larger than in the constant returns to scale sector. As in Venables (1996), we ignore the issue of migration between regions, which might be justified on the ground that migrations between European countries are fairly low (see Decressin and Fatás, 1995; Bentolila 1997 and Faini, Galli, Gennari and Rossi, 1997).

As usual in economic geographic models, firms from the modern industry are willing to locate their production in regions where the demand for their product is large in order to save on transport costs. The size of the demand in a region depends on the numbers of workers who have invested in education and earn large wages relative to the number of workers who remain unskilled and earn low wages. Hence firms from the modern sector want to settle at the proximity of high-wage skilled workers. In addition, more workers decide to invest in education when more firms ask for skilled workers in their own

\footnotetext{
${ }^{2}$ See also Fujita and Thisse (2002) and Ottaviano, Tabuchi and Thisse (2002) for linear models that are analytically tractable.
} 
region. The proportion of skilled workers increases with the number of firms in a region. As a result, if firms move towards a region, more workers from that region are induced to become skilled. In turn, this raises the demand in that region and reinforce the movement of firms to that region. The circular causality that was lost in the basic footloose capital model is now re-introduced through the modelling of skill acquisition. Despite this slight modification, the model remains analytically tractable and allows to get a closed-form solution for the location of firms. This model could therefore prove useful to analyze other policy implications.

We show that if subsidies are equal in both regions, firms spread evenly across regions for large transport costs whereas they agglomerate in a core region for low transport costs. When subsidies differ across regions, firms partially agglomerate in the low subsidy region for large transport costs, they partially agglomerate in the high subsidy region for intermediate transport costs and they fully agglomerate for low transport costs. In that case, the core produces the whole of the differentiated products and export these products to the periphery whereas the periphery exports the good produced under constant returns to scale. In contrast with existing literature, agglomeration is explained by differences between wages of skilled and unskilled workers. Moreover, the model exhibits equilibria with partial agglomeration of firms for which we derive an explicit closed-form solution.

We also explore to what extend a change in the subsidy in one region may be welfare-improving. We show that for low transport costs, a change in the subsidy has a minor impact on firms' location and on welfare. The incentive to compete on educational subsidies is low. In contrast, for larger transport costs, a change in the subsidy strongly affects firms' location and welfare. In that case, local governments have a strong incentive to compete on educational subsidies: the government that affords the largest subsidy is in good position to attract firms and improve welfare.

The paper is organized as follows. Section 2 presents the basic coreperiphery model. Section 3 analyzes firms' location. In that section, we start with a simple case in which both local governments set identical subsidies. Then we examine firms' location when subsidies are differentiated. Finally we explore the issue of the optimal subsidy set by a local government. This 
is followed by the conclusions.

\section{The Model}

\subsection{Consumption}

The model builds on Dixit-Stiglitz (1977). Preferences are represented by a Cobb-Douglas function with a share $\mu \in(0,1)$ of income spent on modern goods (the manufactured goods) and a share $1-\mu$ spent on a traditional good that is produced under constant returns to scale (the agricultural good). The modern good is a composite made of a continuum of differentiated varieties $i \in[0, N]$. Preferences for these varieties are represented by a CES function with an elasticity of substitution equal to $\sigma>1$. Accordingly, the demand for variety $i$ by households located in region $r$ is as follows:

$$
C_{r}(i)=\frac{\mu Y_{r}}{P_{r}}\left[\frac{\varsigma_{r}(i)}{P_{r}}\right]^{-\sigma} \quad i \in[0, N]
$$

where

$$
P_{r} \equiv\left[\int_{0}^{N} \varsigma_{r}(i)^{-(\sigma-1)} d i\right]^{-1 /(\sigma-1)}
$$

is the price index of the varieties sold in region $r, \varsigma_{r}(i)$ the price paid by a household located in region $r$ for one unit of variety $i$, and $Y_{r}$ the income available in region $r$.

The traditional good is traded at no cost, whereas the proportion $0<$ $\phi<1$ of a single unit of each variety of the modern goods shipped from one region arrives in the other region (the iceberg transport cost). Therefore, if variety $i$ is consumed in the region where it is produced, the price paid by the households residing in this region, $\varsigma_{r}(i)$, is equal to the mill price $p_{r}(i)$. If variety $i$ is consumed in the other region $s$, then the price paid by a household equals the delivered price, which exceeds the mill price; $\varsigma_{s}(i)=p_{r}(i) / \phi>p_{r}(i)$. For notational convenience we define $\Phi \equiv \phi^{\sigma-1}$ which is an indicator of trade openness.

Accordingly, the price level of modern goods is

$$
P_{r}=\left\{\int_{0}^{n_{r}} p_{r}(i)^{-(\sigma-1)} d i+\Phi \int_{n_{r}}^{N} p_{s}(i)^{-(\sigma-1)} d i\right\}^{-1 /(\sigma-1)}
$$


where $n_{r}$ denotes the number of varieties produced in region $r$ (with $n_{r}+n_{s}=$ $N$ ). Given (1), the demand for output of a firm $i$ that is established in region $r$ is

$$
q_{r}(i)=\psi_{r}\left[\frac{p_{r}(i)}{P_{r}}\right]^{-\sigma}
$$

where

$$
\psi_{r} \equiv \mu\left[\frac{Y_{r}}{P_{r}}+\Phi\left(\frac{P_{s}}{P_{r}}\right)^{\sigma} \frac{Y_{s}}{P_{s}}\right]
$$

is the total real income adjusted for transport costs.

\section{$2.2 \quad$ Firms}

The model is a variant of the footloose capital model developed by Martin and Rogers (1995). Each firm requires one unit of capital. There exists $N$ units of capital available worldwide. Capital is mobile but their owners are immobile: they repatriate the revenues to the region where they live. Fifty percent of capital owners live in each region. Accordingly, $N$ firms are active in the economy.

Each variety is produced by a single firm and the production of one unit of variety $i$ requires $\beta$ skilled workers; without loss of generality, we normalize $\beta=1$ so that the number of units produced by a firm is equal to the number of workers it employs. Because firms from the modern industry have market power, they may earn profits. However they compete for the available units of capital so that all profits are distributed to capital owners.

Suppose that firm $i$ is located in region $r$. Its profits (gross of capital costs) are defined as follows

$$
\pi_{r}(i)=\left[p_{r}(i)-w_{r}\right] q_{r}(i)
$$

where $w_{r}$ is the wage prevailing in region $r$ whereas the demand $q_{r}(i)$ is given by (2). Since there is a continuum of firms in the modern industry, each of them is negligible and accurately considers the price index $P_{r}$ as given. The firm producing variety $i$ chooses its mill price to maximize its profits $\pi_{r}(i)$, which yields the same equilibrium price given by:

$$
p_{r} \equiv p_{r}(i)=\frac{\sigma}{\sigma-1} w_{r}
$$


The demand for labor of firm $i$ producing in region $r$ is:

$$
l_{r}(i)=q_{r}(i) \equiv q_{r}=\psi_{r}\left[\frac{\sigma}{\sigma-1} \frac{w_{r}}{P_{r}}\right]^{-\sigma}
$$

Using (2), it is easy to show that the gross profits made by a firm located in region $r$ are such as

$$
\pi_{r}=\frac{1}{\sigma}\left(\frac{\sigma}{\sigma-1} \frac{w_{r}}{P_{r}}\right)^{1-\sigma} P_{r} \psi_{r}
$$

\subsection{Labor}

It is a stylized fact of European labor markets that workers are rather immobile between European countries and within each country (see e.g. Decressin and Fatás, 1995; Bentolila, 1997; Faini, Galli, Gennari and Rossi, 1997). To fit this European fact, we assume that workers cannot move across regions. This contrasts with Krugman (1991) who mainly focuses on the long-run behavior of workers in the United States.

Each region is populated by the same number of individuals, $\bar{L}$, who can work either in the traditional or in the modern sector. We assume that individuals are able to work in both sectors. However, to work in the modern sector, an individual has to invest in education, which reduces his/her leisure time. If $L_{r}$ persons have invested in education, the remaining $\bar{L}-L_{r}$ workers must be employed in the traditional sector. The traditional good is produced under constant returns to scale. One unit of the traditional good requires one unit of labor. Since the traditional good is the numeraire, wages are equal to one in this sector.

All individuals are a priori alike. The utility derived from leisure and consumption is supposed to be Cobb-Douglas: (Leisure $)^{\gamma} *(\text { sub-utility from consumption })^{1-\gamma}$. By suitable transformations, this utility is equivalent to (Leisure) $)^{\gamma /(1-\gamma)} *$ (sub-utility from consumption). Finally, set (Leisure $)^{\gamma /(1-\gamma)}=1$ for unskilled workers and (Leisure $)^{\gamma /(1-\gamma)}=1 /(1+d)$ for skilled workers where $d$ is some given positive constant. Given the preferences for the traditional good and the differentiated varieties, the utility derived from consumption is the real wage, that is, either $1 / P_{r}^{G}$ for unskilled workers living in region $r$ or $w_{r} / P_{r}^{G}$ for the skilled workers. The variable $P_{r}^{G}$ denotes the general price index of both traditional and modern goods consumed in region $r$. 
For some individuals to work in the modern sector and others in the tarditional sector, wages in the modern sector must compensate for the loss of utility:

$$
\frac{1}{1+d} \frac{w_{r}}{P_{r}^{G}}=\frac{1}{P_{r}^{G}} \Longleftrightarrow w_{r}=1+d
$$

Wages of skilled workers must be larger than wages of unskilled workers.

In each region, a local government can help workers to become skilled by granting them a subsidy $s_{r}$ aimed at reducing the costs of education. Thus, the revenue from being skilled is now $w_{r}+s_{r}$ rather than $w_{r}$. As a consequence, wages in region $r$ are now

$$
w_{r}=1+d-s_{r}
$$

The net revenue of workers in the modern sector is therefore equal to $w_{r}+s_{r}=1+d$. The subsidy granted to skilled workers is equivalent to a direct subsidy to firms per employee they hire. This is a consequence of the assumption that all individuals are alike. To avoid situations in which nobody remains unskilled in one region, we assume that $d-s_{r} \geq 0$.

In each region, the total earnings are $Y_{r}=\left(\bar{L}-L_{r}\right)+L_{r}(1+d)+\Pi / 2-$ $T_{r}$, that is, they are respectively made of revenues of individuals working in the traditional sector, workers from the modern sector, half the total gross profits of both regions $\Pi$, minus the taxes paid to finance the government, $T_{r}$. Under balanced budget, $T_{r}=s_{r} L_{r}$ and

$$
Y_{r}=\bar{L}+L_{r}\left(d-s_{r}\right)+\frac{\Pi}{2}
$$

\section{Location Equilibrium}

We assume that firms are myopic, that is, the driving force in firms' location is firms' current profit differential between $r$ and $s, \Delta \pi\left(n_{r}\right)=\pi_{r}(i)-\pi_{s}(i)$ :

$$
\frac{d n_{r}}{d t}=\left\{\begin{array}{c}
\Delta \pi\left(n_{r}\right) \text { if } 0<n_{r}<1 \\
\min \left\{0, \Delta \pi\left(n_{r}\right)\right\} \text { if } n_{r}=N \\
\max \left\{0, \Delta \pi\left(n_{r}\right)\right\} \text { if } n_{r}=0
\end{array}\right.
$$

where $t$ is time. This assumption is standard in the literature (see e.g. Fujita, Krugman and Venables, 1999; Ottaviano, Tabuchi and Thisse, 2002). A 
location equilibrium is interior $\left(n_{r}^{*} \in(0, N)\right)$ if $\Delta \pi\left(n_{r}^{*}\right)=0$; it is the corner $n_{r}^{*}=0$ if $\Delta \pi(0) \leq 0$ and it is the corner $n_{r}^{*}=N$ if $\Delta \pi(N) \geq 0$. A spatial location equilibrium is stable if, for any marginal deviation from the equilibrium, the equation of motion brings the distribution of firms back to the original one. As a result, any interior location equilibrium is stable if and only if $\Delta \pi$ is a decreasing function around $n_{r}^{*}$. Any corner location is stable when it is an equilibrium.

In order to evaluate $\Delta \pi\left(n_{r}\right)=\left(p_{r}-w_{r}\right) q_{r}-\left(p_{s}-w_{s}\right) q_{s}$, we need to compute prices and output. Since wages are constant, the mill prices (4) are equal to $\left(1+d-s_{r}\right) \sigma /(\sigma-1)$. Hence, the profit differential between regions $r$ and $s$ becomes

$$
\pi_{r}-\pi_{s}=\frac{1+d-s_{r}}{\sigma-1}\left(q_{r}-\frac{1}{D} q_{s}\right) \text { where } D \equiv \frac{1+d-s_{r}}{1+d-s_{s}}=\frac{w_{r}}{w_{s}}
$$

The determination of $q_{r}$ is more complex. To find it, we need to compute the values of $P_{r}$ and $\psi_{r}$. In region $r$, the consumption of one unit of good produced in that region costs $\left(1+d-s_{r}\right) \sigma /(\sigma-1)$ whereas the consumption of one unit of good produced in the other region costs $\left(1+d-s_{s}\right) \sigma / \phi(\sigma-1)$. Therefore, the regional price indices of goods in the modern sector can be written as

$$
P_{r}=\frac{\sigma}{\sigma-1}\left(1+d-s_{r}\right)\left(n_{r}+n_{s} \Phi D^{\sigma-1}\right)^{\frac{-1}{\sigma-1}}
$$

Using (7), the expression of $\psi_{r}$ can be simplified to

$$
\psi_{r}=\frac{\mu}{P_{r}}\left[Y_{r}+\frac{n_{r}+n_{s} \Phi D^{\sigma-1}}{n_{s}+n_{r} \Phi D^{1-\sigma}} \Phi D^{1-\sigma} Y_{s}\right]
$$

In the appendix we use (5), (7) and (8) to find expressions for $Y_{r}, Y_{s}, q_{r}$ and $q_{s}$.

We first develop a simple case where both regions are identical: $s_{r}=s_{s}$. Then we examine two regions that set different subsidies. Finally we give some indications on the way the government of one region can improve the welfare in its own region by modifying the subsidy.

\subsection{Identical regions}

Under identical regions, $s_{s}=s_{r}$, and $D=1$. Using the values of $q_{r}$ and $q_{s}$ derived in the Appendix, it is readily checked that the profit differential 
becomes

$$
\begin{gathered}
\pi_{r}-\pi_{s}=\left(N-2 n_{r}\right) K_{2}(\Phi-\hat{\Phi}) \\
\text { where } \hat{\Phi} \equiv \frac{\sigma\left(1+d-s_{r}\right)-\mu(\sigma-1)\left(d-s_{r}\right)}{\sigma\left(1+d-s_{r}\right)+\mu(\sigma-1)\left(d-s_{r}\right)} \\
K_{2} \equiv-\mu K_{A}(1-\Phi) \frac{\sigma\left(1+d-s_{r}\right)+\mu(\sigma-1)\left(d-s_{r}\right)}{1+d-s_{r}}<0
\end{gathered}
$$

and $K_{A}$ is positive and defined in the Appendix. As the following proposition and Figure 1 indicate, the sole interior equilibrium is the symmetric equilibrium where $n_{r}=N / 2$, and it is stable if and only if $\Phi<\hat{\Phi}$.

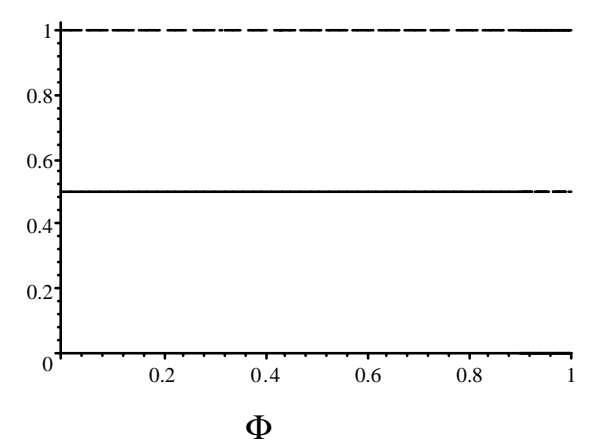

Figure 1: Share of firms in region r. Stable equilibria in plain and unstable in dash. $s=5, \mu=.7, s_{s}=.01, s_{r}=0$, $d=.1$, which gives $F=0.90$.

Proposition 1 Symmetric location $\left(n_{r}=N / 2\right)$ is the unique stable equilibrium if $\Phi<\hat{\Phi}$. Agglomeration in one region is a stable equilibrium if $\Phi>\hat{\Phi}$.

Proof. Stable equilibria are given by the behavior of $\pi_{r}-\pi_{s}$. The equilibrium $n_{r}=N / 2$ is stable when $\pi_{r}-\pi_{s}$ decreases with $n_{r}$. Because $K_{2}<0$, the equilibrium is stable if and only if $\Phi<\hat{\Phi}$. There exist corner equilibria when the profit differential is positive at $n_{r}=N$, and negative at $n_{r}=0$, that is, when $\Phi>\hat{\Phi}$.

The location pattern results from the trade-off between two forces: product market competition and home market effect. To avoid tough competition, firms locate away from competitors. However, to benefit from the home 
market effect, they settle at the proximity of high-wage skilled workers, i.e., at the proximity of the other firms.

For large transport costs (low $\Phi$ ), the effect of product market competition dominates. Exports are negligible and firms produce for their domestic market. If domestic markets have equal sizes, firms locate where competition is the lowest, that is, in the region with the smallest number of firms. Hence, the location equilibrium is symmetric.

However, when the transport cost drops, firms can serve both markets and they suffer from competitors settled in both regions. Since it becomes more difficult to avoid competition, the main force driving firms' location is the home market effect. The relocation of firms to a region induces more workers to become skilled in that region and fewer workers to become skilled in the other region. As a consequence, the number of high-wage skilled workers, the earnings and the product demand rise in the first region whereas they decrease in the other. Since firms are attracted towards the region with the larger demand, they tend to cluster in a single region. When the home market effect is larger than the competition effect $(\Phi>\hat{\Phi})$, agglomeration is the location equilibrium. Since globalization is characterized by decreasing transport costs, it leads to increased agglomeration.

Any factor that strengthens the home market effect fosters agglomeration of firms in a single region. A larger share of the modern goods in the individual's spending (larger $\mu$ ) increases the effect of the home market. Therefore, the set of economic parameters supporting symmetric location equilibria is smaller (the transport cost threshold $\hat{\Phi}$ decreases in $\mu$ ). In the same spirit, larger wages (via a larger cost of education $d$ or a lower subsidy $s_{r}$ ) increases the revenues of skilled workers in the modern industry and therefore strengthens the home market effect. Hence the value of $\hat{\Phi}$ is reduced. In contrast, when it is not costly to become skilled $\left(d-s_{r}=0\right)$, wages are equal for both types of workers and there is no interest to locate at the proximity of skilled workers anymore. The home market effect vanishes and the only equilibrium is the symmetric location of firms $(\hat{\Phi}=1)$.

Finally, and more surprisingly, a more elastic product demand $(\sigma)$ promotes agglomeration. In Krugman, a more elastic product demand fosters symmetry. This result may seem intuitive: a more elastic demand means 
more competition between firms and a stronger incentive to avoid competition. Hence firms from the core prefer to settle away from competitors, which fosters a symmetric location of firms. As intuitive this explanation may seem, it is not satisfactory. Indeed, a rise in $\sigma$ increases competition in the core but also in the periphery where firms suffer from stronger competitions from firms established in the core. Hence it is not clear that firms effectively manage to avoid competition by settling in the periphery. The result of this section suggests that the impact of the demand elasticity on firms' location is not straightforward. ${ }^{3}$

Note that the threshold $\hat{\Phi}$ does not depend on fixed costs, $f$. Hence, increasing returns to scale are not a necessary condition for agglomeration when the number of varieties is fixed. See Picard, Thisse and Toulemonde (2002) for a detailed analysis of the role of increasing returns to scale and profit distribution in economic geography models.

\subsection{Different regions}

Let us now examine the case in which both regions set different subsidies. Without loss of generality, we assume that $s_{s}>s_{r}$, which implies that wages are larger in region $r$ and $D>1$. As shown in the appendix, the profit differential can be written as

$$
\pi_{r}-\pi_{s}=\mu K_{A} D^{\sigma}\left(-\operatorname{Den} * n_{r}+\mathrm{Num}\right)
$$

where

$$
\begin{aligned}
\text { Den }= & \left\{2 \sigma+\mu Z_{r}\left[D\left(d-s_{s}\right)+\left(d-s_{r}\right)\right]\right\} \Phi^{2} \\
& -2 \sigma D^{\sigma-1}\left[1+D^{2(1-\sigma)}\right] \Phi+2 \sigma-\mu Z_{r}\left[D\left(d-s_{s}\right)+\left(d-s_{r}\right)\right] \\
\text { Num }= & N\left\{\left[\sigma+\mu Z_{r} D\left(d-s_{s}\right)\right] \Phi^{2}-2 \sigma D^{\sigma-1} \Phi+\sigma-\mu Z_{r} D\left(d-s_{s}\right)\right\}
\end{aligned}
$$

For an interior equilibrium, $\pi_{r}-\pi_{s}=0$, which requires $n_{r}^{*}=\mathrm{Num} /$ Den. We analyze this expression in the appendix where we first prove that the

${ }^{3}$ The result also contrats with Picard and Toulemonde (2002) despite the closeness of the two models. The main difference lies in the wage determination. In Picard and Toulemonde (2002), wages decrease when goods become closer substitute because the rent that is shared between firms and unions is smaller. The decrease in wages reduces the agglomeration force and induces firms to locate more symmetrically; this force does not exist in the present model where wages are independent of $\sigma$. 
numerator only has one root in $\Phi$ on the relevant domain $\Phi \in[0,1]$. We then prove the same result for the denominator. Numerical simulations indicate that the root of the numerator is always smaller than the root of the denominator. Moreover, at $\Phi=0, n_{r}^{*}>N / 2$.

As illustrated in Figure 2, the function $n_{r}^{*}$ starts above $N / 2$ (slightly above $N / 2$ for the parameters chosen to draw the figure), it decreases to zero (the root of the numerator) and then has a vertical asymptote at the root of the denominator (the asymptote is not drawn in the figure). After the asymptote, $n_{r}^{*}$ tends to the infinity and decreases; depending on parameters, it may fall below $N$ (the dash curve in panel b of the figure) or not (panel a of the figure). However it always stays larger than 0 .

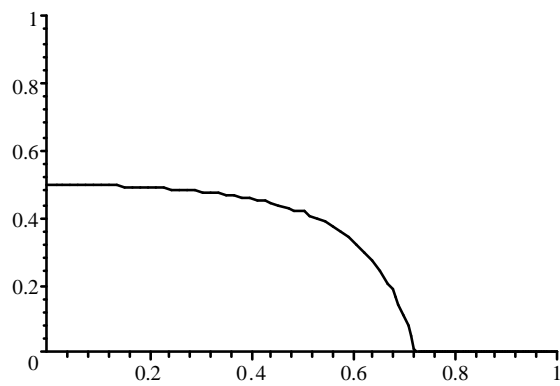

(a)

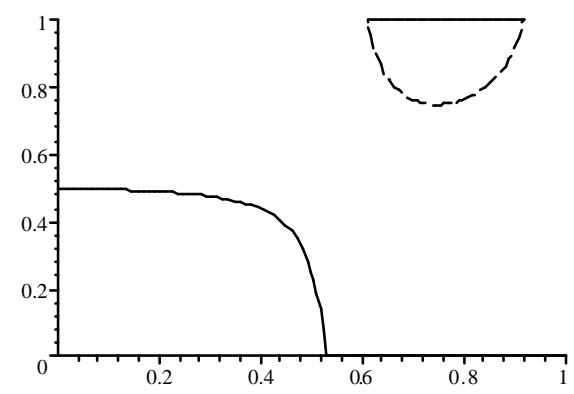

(b)

Figure 2: Share of firms in region $r$. Stable equilibria in plain and unstable in dash. $s=5, \mu=.7$, $s_{s}=.01, s_{r}=0$. In panel (a) $d=.1$, whereas $d=1$ in panel (b).

The interior equilibrium is stable if and only if the derivative of $\pi_{r}-\pi_{s}$ with respect to $n_{r}$ is negative at the equilibrium, i.e., if and only if Den is positive. Den is positive at the left of the vertical asymptote and negative at the right. Hence, if it exists, the interior equilibrium is stable at the left of the asymptote and unstable at the right of it. Depending on the agglomeration force, unstable interior equilibrium may exist: in the left panel, it does not exist for $\sigma=5, \mu=0.7, s_{r}=0, s_{s}=.01$ and,$d=0.1$ whereas it exists for the same values of parameters and $d=1$.

By continuity of the profit differential function, agglomeration cannot be stable when the (sole) interior equilibrium is stable. Indeed, the function decreases when it is equal to zero and must therefore be negative in case of 
agglomeration in region $r$ and positive in case of agglomeration in the other region. By the same argument, agglomeration in either region $r$ or region $s$ is stable if there exists an unstable interior equilibrium. Finally, when there exists no stable interior equilibrium (that is, when $n_{r}^{*}>N$ or $n_{r}^{*}<0$ ), the profit differential is negative and the only equilibrium is agglomeration in region $s$.

The location pattern results from the trade-off between three forces: product market competition, wage differential effect and home market effect. Product market competition induces firms to settle away from each other, that is, to spread evenly across regions. To reduce their costs, firms prefer the region with the lowest wages; this is the wage differential effect. However, they also prefer the region where the demand is the highest. Since the demand is positively related to wages, they are attracted to the region where wages are higher. They are also attracted towards the region where most firms are located. This is the home market effect.

At prohibitive transport costs $(\Phi=0)$, it is not possible to export the production. Therefore, by spreading across regions, firms effectively manage to avoid competition from firms established in the other region. Product market competition is the leading force. Costs are lower in region $s$ because education is subsidized there. However the home market effect also plays a role. Suppose that there is the same number of skilled workers $(\hat{L})$ in both regions. In region $r$, earnings are $\bar{L}+\hat{L} d+\Pi / 2$ whereas they are $\bar{L}+\hat{L} d-\hat{L} s_{s}+\Pi / 2$. That is, earnings are lower in region $s$ because of the taxes paid to finance education. Since transport costs are prohibitive, it is not possible for a firm to settle in the low cost region and export to the high demand region. To match the large demand, more than 50 percent of firms settle in region $r$, which is the high wage region $\left(n_{r}^{*}>N / 2\right)$. In the simulations, we set $\sigma=5$ and $\mu=0.7$ and we fix low values for the cost of education $(d=0.1)$ and for the subsidy in region $s\left(s_{s}=0.01\right)$. We use low values for $d$ and $s_{s}$ in order to depart as little as possible from a more standard model with no subsidy and in which it is not costly to become skilled. Under these values at most $50.3 \%$ of firms settle in the high wage region (when $\left.s_{r}=0\right)$. Once we increase the cost of education $(d=1)$ and the subsidy set in region $s\left(s_{s}=1\right.$, which reduces wages in region $\left.s\right)$, up 
to $91 \%$ of firms may settle in the high wage region $r$. More generally, the larger is the difference between subsidies in the two regions $\left(s_{s}-s_{r}\right)$ and the more costly it is to become skilled, the larger is the wage differential and the home market effect: more firms settle in the high wage region.

When the foreign region becomes accessible (through a reduction in transport costs), product market competition becomes less influential because it is more difficult to avoid competition by changing location. In contrast, it becomes possible to benefit from low wages in region $s$ and at the same time to serve the large market $r$. It is therefore less attractive to settle in region $r$ : partial agglomeration in that region is reduced and even vanishes at some threshold value of the transport costs: the benefit from low costs outweighs the advantage of settling in the large wage region; partial agglomeration now occurs in region $s$.

Globalization weakens the relative influence of product market competition and exacerbates the effect of costs differences on firms location: as $\Phi$ is increased, partial agglomeration is fostered in the region with the lowest wages. As region $s$ hosts more firms, it also increase its wage bill, which fosters the demand coming from that region. The home market effect now favors the high subsidy region because the number of high wage skilled workers is larger there. This contributes to accelerate agglomeration in the low wage region until complete agglomeration in that region.

For low transport costs, the market competition force becomes so weak that it is dominated by the two other forces. If the home market effect is weak (low value of the cost of education $d$ ), the wage differential remains the leading force and agglomeration in the low wage region is the only stable equilibrium. In contrast, if the home market effect is stronger (large $d$ ), agglomeration in the high wage region becomes feasible: if all firms are located there, the demand becomes so high that firms do not want to settle in the low wage region. This situation is similar to the context of tax competition analyzed by Ludema and Wooton (2000) and by Kind, Midelfart Knarvik and Schjelderup (2000): they show that there may be agglomeration in a region with higher taxes because firms earn higher profits when they are located near a large agglomeration of firms. Since their only alternative is to settle in a region without a concentration of firms, the core region may 
extract some of the agglomeration rent through higher taxes without losing firms (see also Baldwin et al., 2003). In our context, taxes are replaced with subsidies to education. If there is agglomeration of firms in the core, the core region can extract some of the agglomeration rent through higher wages (via lower subsidies). However when the transport cost vanishes ( $\Phi$ close to 1), the home market effect also disappears because it is possible for all firms to serve both markets at no extra cost. Therefore, firms agglomerate in the low wage (high subsidy) region.

In line with the literature, these results confirm that globalization induces more agglomeration; as a complement to the literature, agglomeration increases smoothly in our setting, which is more realistic than the sudden jumps emphasized in most existing models. In contrast to the literature, for a given set of parameters, we do not have interior equilibria coexisting with complete agglomeration.

\subsection{Optimal subsidies}

In this section we give some indications on the way the government of one of the two regions could improve welfare in its own region by manipulating the subsidy accorded for skill acquisition. Despite its analytical tractability, the model does not allow to completely answer the question. Nevertheless, using simulations, it is possible to give insights of the main forces that drive governments' behavior. As in previous analysis, we assume that region $s$ set a larger subsidy than region $r$, and thus, wages are lower in region $s$. 


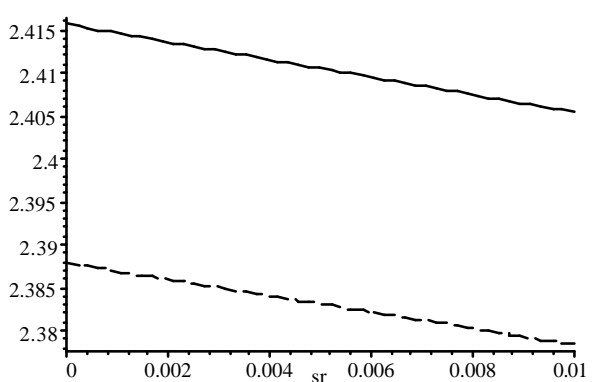

(a)

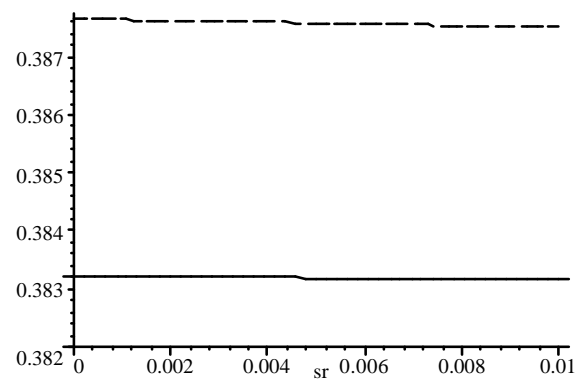

(c)

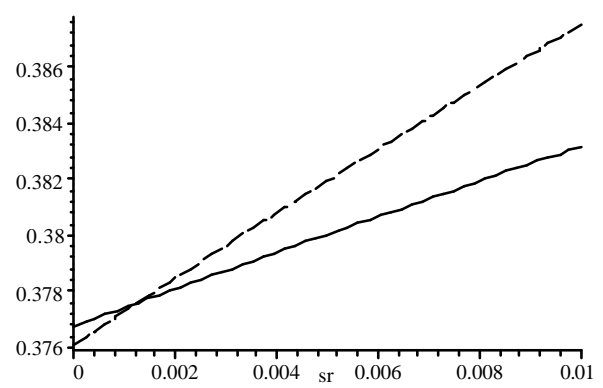

(e)

Figure 3: General price level (panel a), nominal earnings (panel b), real earnings (panel c), firms' location (panel d) and welfare in region $\mathrm{r}$ as a function of $s_{r}$, when $F=0.5$ (plain) and $F=0.6$ (dash). The two curves are nearly identical in panel b. Panels a, b and c are drawn for $n_{r}=0.5$. Other parameters are $s=5, \mu=.7, d=.1, s_{s}=.01, N=1, f=.5, L=1$.

To determine the optimal value of subsidies set by the two independent governments, we need to define the welfare function that governments optimize. In our setting, workers are indifferent between becoming skilled or remaining unskilled. Therefore all workers are alike and get the same utility level. In that setting, and because of linearly homogenous preferences, a 
natural measure of welfare in region $r$ is the real earnings in that region, that is, $Y_{r} / P_{r}^{G}$ where $P_{r}^{G}$ is the general price index of both traditional and modern goods consumed in region $r$ and is defined as

$$
P_{r}^{G}=\left(\frac{P_{r}}{\mu}\right)^{\mu}\left(\frac{1}{1-\mu}\right)^{(1-\mu)} \equiv\left(P_{r}\right)^{\mu} \frac{1}{\mu_{0}} .
$$

We do not examine here the case in which full agglomeration emerges as an equilibrium $^{4}$; we rather restrict ourselves to partially asymmetric equilibria ${ }^{5}$. Doing so, we are able to examine the impact of subsidies when changes of firms' location is not catastrophic.

A change in the subsidy set by region $r$ has three effects. A direct impact on nominal earnings $Y_{r}$, another on the price level $P_{r}^{G}$, and an indirect impact on these two variables through variations in the firms' location. This last effect is easily traced: everything else equal, an increase in the number of firms in region $r$ raises the earnings $Y_{r}$ and reduces the price level $P_{r}^{G}$ in that region: more high wage skilled workers are employed in that region and more goods are produced locally and do not have to be imported from the other region. An increase in $n_{r}$ is therefore good for welfare.

Let us examine to what extent an increase in the subsidy in region $r$ affects firms' location, $n_{r}$. Since an increase in the subsidy in region $r$ reduces wages in that region, it also induces more firms to settle in region $r$. Simulations suggest that the effect of a change in $s_{r}$ on firms' location is stronger when the transport costs is smaller. This is illustrated in panel $\mathrm{d}$ of the figure, where it is shown that for low transport costs, firms' location strongly responds to a change in the subsidy $s_{r} .{ }^{6}$ Therefore, we can expect that globalization (a reduction in the transport cost) exacerbates the incentive to use subsidies to attract firms and increase the local welfare. In contrast, when transport costs are smaller, a change in the subsidy does not

\footnotetext{
${ }^{4}$ See Ludema and Wooton (2000) for this kind of analysis in a tax competition framework.

${ }^{5}$ Thus, $\Phi$ must be small enough to prevent full agglomeration.

${ }^{6}$ Note that for prohibitive transport costs ( $\Phi$ close to zero), it is possible that $n_{r}$ decreases with $s_{r}$ : an increase in the subsidy reduces wages and earnings in region $r$, which deters firms from that region. However simulations suggest that this effect is weak and limited to a small domain of $\Phi$.
} 
strongly affect firms location, which reduces the incentive to use subsidies as a way to attract new firms.

The direct effect of subsidies on the price level is straightforward: they reduce the costs, and by this way the price set by each firm and the general price level. Hence, through this effect, subsidies increase welfare. Panel a of Figure 3 shows a simulation for a value of $n_{r}$ set at 0.5 , which is the value reached when both governments choose the same subsidies $\left(s_{r}=s_{s}=0.01\right)$. The figure shows that holding everything else constant (including $n_{r}=0.5$ ), a reduction in the subsidy $s_{r}$ increases the price level.

By contrast, the direct effect through earnings is stronger. An increase in subsidies in region $r$ reduces wages in that region but leaves net revenues unchanged. Its effect on earnings is negative because taxes are raised. However, because costs are reduced, profits and output are larger, which raises earnings. Nevertheless simulations show that the net effect of an increase in subsidies is to decrease nominal earnings. ${ }^{7}$ Panel b of Figure 3 illustrates the result. Holding everything else constant, a reduction in the subsidy $s_{r}$ increases the nominal earnings.

Combining both direct effects (on earnings and prices, holding $n_{r}$ constant), simulations indicate that subsidies reduce welfare. This is illustrated in panel $\mathrm{c}$ of the figure.

The global effect of subsidies on welfare combines the two direct effects and the indirect effect. Every simulation that was done showed that the global effect is positive: an increase in subsidies raises welfare. There is room for a "subsidy competition". When transport costs are low, the indirect effect through firms' location is weak and thus, the increase in welfare through a raise in subsidies is small. This is represented by the plain curve in panel e of the figure. By contrast, when transport costs are reduced, a small change in subsidies strongly affect firms' location which in turn strongly impacts on welfare. The incentive to use subsidies increases. Hence, globalization increases the incentives to use subsidies as a way to attract firms and to increase welfare.

\footnotetext{
${ }^{7}$ Note that for prohibitive transport costs $\left(\Phi\right.$ close to zero), it is possible that $Y_{r}$ increases with $s_{r}$. However simulations suggest that this effect is weak and limited to a small domain of $\Phi$.
} 


\section{Conclusions}

This paper develops an analytically solvable model of the new economic geography that exhibits a core-periphery structure. Workers who invest in education earn larger wages than workers who remain unskilled. Firms want to locate their production in regions where the demand for their product is large in order to save on transport costs. The size of the demand in a region depends on the numbers of workers who have invested in education and earn large wages relative to the number of workers who remain unskilled and earn low wages. Hence firms want to settle at the proximity of highwage skilled workers. In addition, workers are eager to invest in education when more firms ask for skilled workers in their own region. Therefore, if firms relocate in a region, more workers from that region are induced to become skilled. In turn, this raises the demand in that region and reinforce the movement of firms to that region. This circular causality implies that for low transport costs, firms agglomerate in a core region. In contrast they partially agglomerate in one region for intermediate and high transport costs. The region that benefits from this partial agglomeration is the low subsidy region when transport costs are prohibitive, whereas it is the high subsidy region when transport costs are intermediate.

The incentive to use education subsidies to attract firms in a region therefore highly depends on the level of transport costs. Globalization (a reduction in transport costs) increases this incentive and may well create a "subsidy competition" in which local governments compete to promote skill acquisition in their own region.

Interestingly, the model allows to derive an explicit closed-form solution, even when agglomeration is partial. This analytical tractability could therefore prove useful to analyze other policy implications of a economic geography models.

\section{References}

F. Andersson and R. Forslid (2003), Tax Competition and Economic Geography, Journal of Public Economic Theory 5, 279-304. 
R. Baldwin, R. Forslid, Ph. Martin, G. Ottaviano and F. Robert-Nicoud (2003), "Economic Geography and Public Policy", Princeton University Press, Princeton, NJ.

R. Baldwin and F. Robert-Nicoud (2000), Free Trade Agreements without delocation, Canadian Journal of Economics, 33, 766-786.

S. Bentolila (1997), Sticky Labor in Spanish Regions, European Economic Review, 41, 591-598.

J. Decressin and A. Fatás (1995), Regional Labor Market Dynamics in Europe, European Economic Review, 39, 1627-1655.

A.K. Dixit and J. Stiglitz (1977), Monopolistic Competition and Optimum Product Diversity, American Economic Review, 67, 297-308.

R. Faini, G. Galli, P. Gennari and F. Rossi (1997), An Empirical Puzzle: Falling Migration and Growing Unemployment Differentials among Italian Regions, European Economic Review, 41, 571-579.

M. Fujita, P. Krugman and A. J. Venables (1999), "The Spatial Economy: Cities, Regions and International Trade", MIT Press, Cambridge, MA.

M. Fujita and J.F. Thisse (2002), "Economics of Agglomeration", Cambridge University Press, Cambridge.

H.J. Kind, K. H. Midelfart Knarvik and G. Schjelderup (2000), Competing for Capital in a Lumpy World, Journal of Public Economics, 78, 253-274.

P.R. Krugman (1991), Increasing Returns and Economic Geography, Journal of Political Economy, 99, 483-499.

P.R. Krugman and A. J. Venables (1995), Globalization and The Inequality of Nations, Quarterly Journal of Economics, 110, 857-880.

R. D. Ludema and I. Wooton (2000), Economic Geography and The Fiscal Effects of Regional Integration, Journal of International Economics, 52, 331-357.

P. Martin and C.A. Rogers (1995), Industrial Location and Public Infrastructure, Journal of International Economy, 39, 335-351. 
J.P. Neary (2001), Of Hype and Hyperbolas: Introducing The New Economic Geography, Journal of Economic Literature, 39, 536-561.

G.I.P. Ottaviano, and J.-F. Thisse (2003), Agglomeration and Economic Geography, CEPR Discussion Paper 3838.

G.I.P. Ottaviano, T. Tabuchi and J.-F. Thisse (2002), Agglomeration and Trade Revisited', International Economic Review, 43, 409-435.

P.M. Picard , J.F. Thisse and E. Toulemonde (2002), Economic Geography and the Distribution of Profits, CEPR Discussion Paper 3385.

P.M. Picard, and E. Toulemonde (2002), Firms Agglomeration and Unions, CEPR Discussion Paper 3323.

D. Puga (1999), The Rise and Fall of Regional Inequalities, European Economic Review, 43, 303-334.

F. Trionfetti (2001). Public Procurement, Market Integration, and Income Inequalities, Review of International Economics, 9, 29-41.

A.J. Venables (1996), "Equilibrium Locations of Vertically Linked Industries", International Economic Review, 37, 341-359. 


\section{Appendix}

Determination of $Y_{r}, Y_{s}, q_{r}$ and $q_{s}$. In each region total profits are equal to the value of production minus labor and fixed costs, $n_{r} \pi_{r}=n_{r}\left(p_{r}-w_{r}\right) q_{r}-$ $n_{r} f$. Hence,

$$
\begin{aligned}
& Y_{r}=\bar{L}+L_{r}\left(d-s_{r}\right)+\frac{\Pi}{2}=\bar{L}-\frac{N f}{2}+\left(d-s_{r}\right) n_{r} q_{r}+\frac{1+d-s_{r}}{\sigma-1} \frac{n_{r} q_{r}+n_{s} q_{s} D^{-1}}{2} \\
& Y_{s}=\bar{L}+L_{s}\left(d-s_{s}\right)+\frac{\Pi}{2}=\bar{L}-\frac{N f}{2}+\left(d-s_{s}\right) n_{s} q_{s}+\frac{1+d-s_{r}}{\sigma-1} \frac{n_{r} q_{r}+n_{s} q_{s} D^{-1}}{2}
\end{aligned}
$$

Earnings $\left(Y_{r}\right.$ and $\left.Y_{s}\right)$ are function of output $\left(q_{r}\right.$ and $\left.q_{s}\right)$. Using (5), (7) and (8), we find other relations between output and earnings:

$$
\begin{aligned}
& q_{r}=\frac{\mu}{1+d-s_{r}} \frac{\sigma-1}{\sigma}\left(\frac{Y_{r}}{n_{r}+n_{s} \Phi D^{\sigma-1}}+\frac{Y_{s}}{n_{s}+n_{r} \Phi D^{1-\sigma}} \Phi D^{1-\sigma}\right) \\
& q_{s}=\frac{\mu}{1+d-s_{s}} \frac{\sigma-1}{\sigma}\left(\frac{Y_{s}}{n_{s}+n_{r} \Phi D^{1-\sigma}}+\frac{Y_{r}}{n_{r}+n_{s} \Phi D^{\sigma-1}} \Phi D^{\sigma-1}\right)
\end{aligned}
$$

Solving the four expressions with four unknowns allows to get $q_{r}, q_{s}, Y_{r}$ and $Y_{s}$ :

$$
\begin{aligned}
q_{r} & =\mu Z_{r} K_{A}\left[\sigma D^{\sigma}\left(\Phi D^{1-\sigma} A_{r}+A_{s}\right)-\mu Z_{r} D^{\sigma+1} n_{s}\left(d-s_{s}\right)\left(1-\Phi^{2}\right)\right] \\
q_{s} & =\mu Z_{r} K_{A}\left[\sigma D^{\sigma+1}\left(\Phi D^{\sigma-1} A_{s}+A_{r}\right)-\mu Z_{r} D^{\sigma+1} n_{r}\left(d-s_{r}\right)\left(1-\Phi^{2}\right)\right] \\
Y_{r} & =\sigma A_{r} K_{A}\left\{\mu Z_{r}\left[\Phi D n_{r}\left(d-s_{r}\right)-D^{\sigma+1} n_{s}\left(d-s_{s}\right)\right]+\sigma A_{s} D^{\sigma}\right\} \\
Y_{s} & =\sigma A_{s} K_{A}\left\{\mu Z_{r}\left[\Phi D^{2 \sigma} n_{s}\left(d-s_{s}\right)-D^{\sigma} n_{r}\left(d-s_{r}\right)\right]+\sigma A_{r} D^{\sigma}\right\}
\end{aligned}
$$

where

$$
Z_{r} \equiv \frac{\sigma-1}{1+d-s_{r}}, A_{r} \equiv n_{r}+n_{s} \Phi D^{\sigma-1}, A_{s} \equiv n_{s}+n_{r} \Phi D^{1-\sigma}
$$

and

$K_{A} \equiv \frac{D^{-\sigma}(2 \bar{L}-N f)}{2 \sigma(\sigma-\mu) A_{s} A_{r}-2 \mu \sigma Z_{r}\left[\left(d-s_{r}\right) n_{r} A_{s}+\left(d-s_{s}\right) D n_{s} A_{r}\right]+\mu^{2} Z_{r} n_{s} n_{r}\left(1-\Phi^{2}\right)\left[2 D Z_{r}\left(d-s_{s}\right)\left(d-s_{r}\right)+D\left(d-s_{s}\right)+\left(d-s_{r}\right)\right]}$

It can be shown that $K_{A}$ is positive. The proof is tedious and available from the author.

Different regions Without loss of generality, we assume that $s_{s}>s_{r}$, which implies that wages are larger in region $r$ and $D>1$. Using the values 
of $q_{r}$ and $q_{s}$ from the preceding appendix, we can write the profit as

$$
\begin{aligned}
& \pi_{r}-\pi_{s}=\mu K_{A} D^{\sigma} * \\
&\left\{\sigma\left[A_{s}\left(1-D^{\sigma-1} \Phi\right)-\left(1-D^{1-\sigma} \Phi\right) A_{r}\right]-\mu Z_{r}\left(1-\Phi^{2}\right)\left[D n_{s}\left(d-s_{s}\right)-n_{r}\left(d-s_{r}\right)\right]\right\}
\end{aligned}
$$

Using the definitions of $A_{r}, A_{s}$ and $n_{s}=N-n_{r}$, we have

$$
\pi_{r}-\pi_{s}=\mu K_{A} D^{\sigma}\left(-\operatorname{Den} * n_{r}+\mathrm{Num}\right)
$$

where

$$
\begin{aligned}
\text { Den }= & \left\{2 \sigma+\mu Z_{r}\left[D\left(d-s_{s}\right)+\left(d-s_{r}\right)\right]\right\} \Phi^{2} \\
& -2 \sigma D^{\sigma-1}\left[1+D^{2(1-\sigma)}\right] \Phi+2 \sigma-\mu Z_{r}\left[D\left(d-s_{s}\right)+\left(d-s_{r}\right)\right] \\
\text { Num }= & N\left\{\left[\sigma+\mu Z_{r} D\left(d-s_{s}\right)\right] \Phi^{2}-2 \sigma D^{\sigma-1} \Phi+\sigma-\mu Z_{r} D\left(d-s_{s}\right)\right\}
\end{aligned}
$$

For an interior equilibrium, $\pi_{r}-\pi_{s}=0$, which requires $n_{r}^{*}=\mathrm{Num} /$ Den. We first prove that the numerator only has one and only one root in $\Phi$ on the relevant domain $\Phi \in[0,1]$. We then prove the same result for the denominator and we combine both results to analyze the fraction $n_{r}^{*}$.

\section{The numerator}

- The numerator is a square expression of $\Phi$; it has two roots in $\Phi$ :

$$
\Phi=\frac{D^{\sigma-1} \sigma \pm \sqrt{\sigma^{2}\left[D^{2(\sigma-1)}-1\right]+\mu^{2} Z_{r}^{2} D^{2}\left(d-s_{s}\right)^{2}}}{\sigma+\mu Z_{r} D\left(d-s_{s}\right)}
$$

- The largest root is larger than 1 because the first term in the numerator is larger than the first term in the denominator $\left(D^{\sigma-1} \sigma>\sigma\right)$ and the second term in the numerator is larger than the second term in the denominator $\left(\sqrt{\sigma^{2}\left[D^{2(\sigma-1)}-1\right]+\mu^{2} Z_{r}^{2} D^{2}\left(d-s_{s}\right)^{2}}>\mu Z_{r} D\left(d-s_{s}\right)\right)$.

The largest root is therefore outside the domain of $\Phi$.

- The smallest root is positive because the square of the first term in the numerator minus the expression under the square root is positive. Indeed, using the definitions of $Z_{r}$ and $D$, we get

$$
\begin{aligned}
& D^{2(\sigma-1)} \sigma^{2}-\sigma^{2}\left[D^{2(\sigma-1)}-1\right]-\mu^{2}\left(\frac{\sigma-1}{1+d-s_{s}}\right)^{2}\left(d-s_{s}\right)^{2} \\
= & \sigma^{2}-\mu^{2}(\sigma-1)^{2}\left(\frac{d-s_{s}}{1+d-s_{s}}\right)^{2}>0
\end{aligned}
$$


- The smallest root is also smaller than 1. Indeed, rearranging, it is readily checked that this root is smaller than 1 if and only if

$$
\begin{gathered}
\sigma\left(D^{\sigma-1}-1\right)-\mu Z_{r} D\left(d-s_{s}\right)<\sqrt{\sigma^{2}\left(D^{2(\sigma-1)}-1\right)+\mu^{2} Z_{r}^{2} D^{2}\left(d-s_{s}\right)^{2}}, \\
\Leftrightarrow-2 \sigma\left(D^{\sigma-1}-1\right)\left(\sigma+\mu Z_{r} D\left(d-s_{s}\right)\right)<0
\end{gathered}
$$

which holds because $D \geq 1$.

Therefore, the numerator changes its sign at most once on the relevant values of $\Phi$. At $\Phi=1$, it is equal to $-2 \sigma N\left(D^{\sigma-1}-1\right)<0$. So the numerator is negative for large $\Phi$ and positive for low $\Phi$.

\section{The denominator}

- The denominator is a square expression of $\Phi$; it has two roots in $\Phi$ :

$$
\frac{D^{\sigma-1} \sigma\left[1+D^{2(1-\sigma)}\right] \pm \sqrt{D^{2(\sigma-1)} \sigma^{2}\left[1+D^{2(1-\sigma)}\right]^{2}-4 \sigma^{2}+\mu^{2} Z_{r}^{2}\left[D\left(d-s_{s}\right)+\left(d-s_{r}\right)\right]^{2}}}{2 \sigma+\mu Z_{r}\left[D\left(d-s_{s}\right)+\left(d-s_{r}\right)\right]}
$$

- The largest root is larger than one. To see this, note that the expression under the square root can be written as

$$
\sigma^{2}\left\{D^{2(\sigma-1)}\left[1+D^{2(1-\sigma)}\right]^{2}-4\right\}+\mu^{2} Z_{r}^{2}\left[D\left(d-s_{s}\right)+\left(d-s_{r}\right)\right]^{2}
$$

First note that under $D \geq 1$, the first brackets is positive. Indeed, it is positive if and only if $D^{\sigma-1}\left[1+D^{2(1-\sigma)}\right]-2>0$, which always holds under $D \geq 1$. Hence, the expression under the square root of $\Phi$ is at least equal to $\mu^{2} Z_{r}^{2}\left[D\left(d-s_{s}\right)+\left(d-s_{r}\right)\right]^{2}$. Assume that it is equal to that value. Then, the largest root of $\Phi$ becomes

$$
\Phi=\frac{D^{\sigma-1} \sigma\left[1+D^{2(1-\sigma)}\right]+\mu Z_{r}\left[D\left(d-s_{s}\right)+\left(d-s_{r}\right)\right]}{2 \sigma+\mu Z_{r}\left[D\left(d-s_{s}\right)+\left(d-s_{r}\right)\right]}
$$

Since the first term in the numerator is larger than the first term in the denominator (we have just checked above that $D^{\sigma-1}\left(1+D^{2(1-\sigma)}\right)-$ $2>0$ ) and the second term in the numerator is equal to that in the denominator, this root is larger than 1. 
- The smallest root takes its largest value for $\mu=0$, which gives

$$
\begin{gathered}
\Phi=\frac{D^{\sigma-1}\left[1+D^{2(1-\sigma)}\right]-\sqrt{D^{2(\sigma-1)}\left[1+D^{2(1-\sigma)}\right]^{2}-4}}{2} . \\
\frac{X-\sqrt{X^{2}-4}}{2}-1
\end{gathered}
$$

It is readily checked that this expression is smaller than one if and only if $D^{\sigma-1}\left[1+D^{2(1-\sigma)}\right]-2>0$, which always holds under $D \geq 1$ (see above). Hence, the smallest root is always smaller than 1.

- Now we prove that the smallest root is always positive. To do that, it suffices to prove that the last two terms under the square root are negative (the first term under the square root is the square of the term outside the square root). These two terms are negative if and only if $-2 \sigma+\mu Z_{r}\left[D\left(d-s_{s}\right)+\left(d-s_{r}\right)\right]<0$. Using the definitions of $Z_{r}$ and $D$, this amounts to

$$
(\sigma-1) \mu\left(\frac{d-s_{s}}{1+d-s_{s}}+\frac{d-s_{r}}{1+d-s_{r}}\right)-2 \sigma<0
$$

Since $\left(d-s_{r}\right) /\left(1+d-s_{r}\right)<1$ and $\left(d-s_{s}\right) /\left(1+d-s_{s}\right)<1$, this expression is at most equal to $2(\sigma-1) \mu-2 \sigma$ which is always negative.

Therefore, the denominator changes its sign once on the relevant values of $\Phi$. At $\Phi=1$, it is equal to $2 \sigma\left\{2-D^{\sigma-1}\left[1+D^{2(1-\sigma)}\right]\right\}<0$. So the denominator is negative for large $\Phi$ and positive for low $\Phi$.

The fraction $n_{r}^{*}$ It was not possible to prove analytically that the root of the denominator is always larger than the root of the numerator. However, all of the numerous numerical simulations that were done show that this property holds.

At $\Phi=0, n_{r}^{*}$ is positive and larger than $N / 2$

Proof. At $\Phi=0$,

$$
n_{r}^{*}=\frac{N}{2} \frac{2 \sigma-2 \mu Z_{r} D\left(d-s_{s}\right)}{2 \sigma-\mu Z_{r}\left[D\left(d-s_{s}\right)+\left(d-s_{r}\right)\right]}
$$

The numerator is larger than the denominator because $2 \mu Z_{r} D\left(d-s_{s}\right)<$ $\mu Z_{r}\left[D\left(d-s_{s}\right)+\left(d-s_{r}\right)\right]$ if and only if $D\left(d-s_{s}\right)<\left(d-s_{r}\right)$ which always 
holds under $s_{r}<s_{s}$. For $n_{r}$ to be positive, it is necessary that the denominator be positive. Using the definitions of $Z_{r}$ and $D$, it is readily checked that the denominator is positive if and only if (9) holds, which is always correct. 


\section{Appendix not for publication: proof that $K_{A} \geq 0$}

We have $K_{A} \geq 0 \Longleftrightarrow$

$$
\begin{aligned}
& K_{B} \equiv 2 \sigma(\sigma-\mu) A_{s} A_{r}-2 \mu \sigma Z_{r}\left[\left(d-s_{r}\right) n_{r} A_{s}+\left(d-s_{s}\right) D n_{s} A_{r}\right]+ \\
& \mu^{2} Z_{r} n_{s} n_{r}\left(1-\Phi^{2}\right)\left[2 D Z_{r}\left(d-s_{s}\right)\left(d-s_{r}\right)+D\left(d-s_{s}\right)+\left(d-s_{r}\right)\right]>0
\end{aligned}
$$

Using the definitions of $Z_{r}$ and $D$, and setting

$$
X_{r} \equiv \frac{d-s_{r}}{1+d-s_{r}} \text { and } X_{s} \equiv \frac{d-s_{s}}{1+d-s_{s}}
$$

we find

$$
\begin{aligned}
& K_{B}=2 \sigma(\sigma-\mu) A_{s} A_{r}-2 \mu \sigma(\sigma-1)\left(n_{r} A_{s} X_{r}+n_{s} A_{r} X_{s}\right) \\
& \quad+\mu^{2}(\sigma-1) n_{s} n_{r}\left(1-\Phi^{2}\right)\left[2(\sigma-1) X_{r} X_{s}+X_{s}+X_{r}\right]>0
\end{aligned}
$$

Note that the largest value of $X_{r}$ and $X_{s}$ is 1 . The strategy is to find the lowest value that this expression can take and show that this value is positive.

\subsubsection{First we show that $K_{B}$ is decreasing with $X_{r}$ (and by sym-} metry of the expression with $X_{s}$ )

The derivative of $K_{B}$ with respect to $X_{r}$ is

$$
-n_{r} \mu(\sigma-1)\left\{2 \sigma A_{s}-\mu n_{s}\left(1-\Phi^{2}\right)\left[2 X_{s}(\sigma-1)+1\right]\right\}
$$

Its largest value is for the largest $\mu$ (i.e., $\mu=1$ ) and for the largest $X_{s}$ (i.e., $\left.X_{s}=1\right)$. At theses values, the derivative is $-n_{r}(\sigma-1)\left[2 \sigma A_{s}-n_{s}\left(1-\Phi^{2}\right)(2 \sigma-1)\right]$. Since $A_{s}=n_{s}+n_{r} \Phi D^{1-\sigma}>n_{s}$, the largest value of the derivative is unambiguously negative. Hence $K_{B}$ is decreasing with $X_{r}$.

The lowest value of $K_{B}$ is for the largest values of $X_{r}$ and $X_{s}$, that is, for $X_{r}=1=X_{s}$. At these values,

$K_{B}=2 \sigma\left[(\sigma-\mu) A_{s} A_{r}-\mu(\sigma-1)\left(n_{r} A_{s}+n_{s} A_{r}\right)+\mu^{2}(\sigma-1) n_{s} n_{r}\left(1-\Phi^{2}\right)\right]$

Note that even though $X_{r}, X_{s}, A_{r}$ and $A_{s}$ depend on $d-s_{r}$ and $d-s_{s}$, there are enough degrees of freedom to fix values of $X_{r}, X_{s}$ and still let $A_{r}$ and $A_{s}$ vary. 
7.0.2 Second we show that the lowest value of $K_{B}$ decreases with $\mu$

The derivative of the last expression with respect to $\mu$ is

$$
-2 \sigma\left\{A_{s} A_{r}+(\sigma-1)\left[n_{s}\left(A_{r}-\mu n_{r}\left(1-\Phi^{2}\right)\right)+n_{r}\left(A_{s}-\mu n_{s}\left(1-\Phi^{2}\right)\right)\right]\right\}
$$

This is negative because $A_{r}=n_{r}+n_{s} \Phi D^{\sigma-1}>\mu n_{r}\left(1-\Phi^{2}\right)$ and $A_{s}=$ $n_{s}+n_{r} \Phi D^{1-\sigma}>\mu n_{s}\left(1-\Phi^{2}\right)$. Therefore, the lowest value of $K_{B}$ is for $\mu=1$, which gives

$$
K_{B}=2 \sigma(\sigma-1)\left[A_{s} A_{r}-\left(n_{r} A_{s}+n_{s} A_{r}\right)+n_{s} n_{r}\left(1-\Phi^{2}\right)\right]
$$

7.0.3 Finally, using the definitions of $A_{r}$ and $A_{s}$, we show that the lowest value of $K_{B}$ cannot be negative

Using $A_{r}=n_{r}+n_{s} \Phi D^{\sigma-1}$ and $A_{s}=n_{s}+n_{r} \Phi D^{1-\sigma}$, the lowest value of $K_{B}$ becomes 0 . Hence $K_{B} \geq 0$ and $K_{A} \geq 0$. 